\title{
Geroprotective effects of Aronia melanocarpa fruit extract on Drosophila
} melanogaster

Elena Y. Platonova, Nadezhda V. Zemskaya, Mikhail V. Shaposhnikov, Denis A. Golubev,

Daria V. Kukuman, Natalya R. Pakshina, Natalia S. Ulyasheva, Vasily V. Punegov, Sergey

A. Patov, Alexey A. Moskalev*

\section{Author information}

\section{Affiliations}

Elena Y. Platonova, Nadezhda V. Zemskaya, MikhailV. Shaposhnikov, Denis A. Golubev, Daria V. Kukuman, Natalya R. Minnikhanova, Natalia S. Ulyasheva, Vasily V. Punegov, Alexey A. Moskalev

Institute of Biology of Komi Science Center of Ural Branch of RAS, 167982, Syktyvkar, Russian Federation

Sergey A. Patov

Institute of Chemistry of Komi Science Center of Ural Branch of RAS, 167982, Syktyvkar, Russian Federation

\section{*Corresponding author}

Correspondence to Alexey A. Moskalev

e-mail: amoskalev@ib.komisc.ru

\section{Contact e-mail addresses:}

Elena Y. Platonova-dega37@yandex.ru

Mikhail V. Shaposhnikov - shaposhnikov@ib.komisc.ru

Nadezhda V. Zemskaya - zemskaya@ib.komisc.ru

Denis A. Golubev - denismeatboy@gmail.com

Daria V. Kukuman - Darya.kukuman@mail.ru

Natalya R. Pakshina -mnr270496@gmail.com

Natalia S. Ulyasheva - ulyasheva-1309@yandex.ru

Vasily V. Punegov - punegov@ib.komisc.ru

Sergey A. Patov - ser-patov@yandex.ru 
Alexey A. Moskalev - amoskalev@ib.komisc.ru

\title{
ORCIDs
}

Elena Y. Platonova - ORCID: 0000-0002-4632-2385

Mikhail V. Shaposhnikov - ORCID: 0000-0002-4625-6488

Nadezhda V. Zemskaya - ORCID: 0000-0002-8746-0020

Denis A. Golubev - ORCID: 0000-0003-0570-8211

Daria V. Kukuman - ORCID: 0000-0002-8505-1135

Natalya R. Minnikhanova - ORCID: 0000-0003-2076-0755

Natalia S. Ulyasheva - ORCID: 0000-0002-3326-055X

Vasily V. Punegov - ORCID: 0000-0001-5493-179X

Sergey A. Patov - ORCID: 0000-0002-5468-989X

Alexey A. Moskalev - ORCID: 0000-0002-3248-1633

\begin{abstract}
Aging and its consequences is one of the main problems of humanity. Phytochemicals such as polyphenols, flavonoids, anthocyanins have great potential as geroprotectors. Plants including Aronia used as dietary supplements are an excellent source of these compounds. We have studied the effects of the ethanol extract from Aronia fruits on Drosophila melanogaster lifespan, locomotor activity, stress resistance (oxidative stress, heat shock and starvation). And also, in order to reveal the influence of Aronia extract applied to different life cycles of Drosophila melanogaster, we selected different dietary schemes for imago: throughout life, during the first two weeks $(1-2)$ and during average age $(4-6$ weeks). It was revealed that the ethanol extract of chokeberry increases the median life expectancy in males and females by $5 \%$ when Drosophila melanogaster is added to the diet for $4-6$ weeks of life. This suggests that intervention even in old age is sufficient to increase lifespan. In addition, no harmful effects of $\mathrm{ABE}$ on locomotor activity were found as an indicator of fly health. We showed that Aronia extract increased stress resistance to hyperthermia and oxidative stress. At the same time, Aronia extract did not significantly affect the resistance of flies to starvation. ABE supplementation has increased expression of heat shock proteins (Hsp27, Hsp68, Hsp83), oxidative stress resistance genes (Keap1, NRF, Sod1), some circadian clock genes (Clk, per) and gene of longevity Sirt1.
\end{abstract}


Keywords Aronia berry extract, Lifespan, Drosophila melanogaster, Geroprotector

\section{Introduction}

Aging can be defined as a process that leads to a progressive decline in physiological integrity and organ dysfunctions (Van Beek et al. 2016). This decline is spreading at all levels of biological organization: molecular, cellular, tissue, and organismic (He and Jasper 2014a; Martel et al. 2019; Wang et al. 2014a). Hormesis is the stimulation of protective cellular mechanisms when exposed to mild stress (Rattan 2008) aiming in maintaining homeostasis that provides long-term positive effects (Calabrese et al. 2015; Rattan 1996; Rattan 2000). Hormesis inducers, so-called hormetins, can activate heat shock proteins and proteasomal degradation of damaged proteins (Beedholm et al. 2004; Verbeke et al. 2001a; Verbeke et al. 2001b) DNA repair (Martel et al. 2019) autophagy (Markaki and Tavernarakis 2011; Ryter and Choi 2013), an antioxidant defense that can promote lifespan increase (Pietsch et al. 2011; Rattan 2015). Hormetins may be food components, including phenolic acids, flavonoids, terpenoids, vitamins, trace elements which have a positive effect on the agerelated quality of life (Calabrese and Blain 2005; Proshkina et al. 2020; Rattan 2015).

Aronia melanocarpa ((Michx.) Elliot) relates to the family Rosaceae. In height, the Aronia bush can reach up to $1-2$ meters, its distinctive feature is dark red, almost black fruits in the form of an apple (Cvetanović et al. 2018; Hudec et al. 2006; Jurikova et al. 2017; Kokotkiewicz et al. 2010) In addition, black chokeberry is known all over the world due to its high content of various polyphenols, phenolic acids, flavonoids, anthocyanins, as well as vitamins and macro - and microelements (Borowska and Brzóska 2016; Cvetanović et al. 2018; Hudec et al. 2006; Jurikova et al. 2017; Kokotkiewicz et al. 2010; Oszmiański and Wojdylo 2005; Paulrayer et al. 2017; Staszowska-Karkut and Materska 2020; Taheri et al. 2013). In past centuries, both in North America and in Russia, natural products (berries, fruits, leaves, stems) were used in traditional medicine (Cvetanović et al. 2018; Jurikova et al. 2017; Kokotkiewicz et al. 2010). It was noted that the anti-inflammatory, antiviral and immunomodulatory effects of the use of decoctions, juices and infusions of chokeberry, which have a positive effect on the health and longevity of the organism (Jurikova et al. 2017; Kokotkiewicz et al. 2010; Staszowska-Karkut and Materska 2020). This means that society is interested in improving the quality of life and health with age, therefore, the current generation relies on the experience of the past, with the use of modern technologies. 
The aging process is known to be associated with multiple changes in the body, including slow down of all biological processes, decrease of the reproductive activity and increase of inflammation (Flatt 2020; Rattan 2004). Recently, acetone extract of chokeberry fruits has shown to increase the median lifespan and locomotor activity in Drosophila (Jo and Imm 2017) The lifespan extending effect was associated with increased expression of superoxide dismutase $(S O D)$, catalase $(C A T)$, glutathione peroxidase $(G P x)$ genes and suppression of the methuselah $(M T H)$ gene (Jo and Imm 2017). It was shown that lifelong use of the polyphenol-rich extracts from blueberry (Peng et al. 2012), cloudberry (Lashmanova et al. 2019), rotten apple (Peng et al. 2011), cranberry (Wang et al. 2015) have positive effects on the Drosophila melanogaster lifespan. But the use of a geroprotector throughout life may be accompanied with increased risk of harmful side effects (Moskalev et al. 2016) and it is also known that the geroprotective effect persists when treated at a certain age. Therefore, in addition to experiments with the use of any substances throughout the life of model organisms, experiments were carried out where the effect of a substance on life expectancy was carried out only at an old age, in order to identify the greatest geroprotective potential of the studied substances. It was found that in adult mice (aged $20-22$ months), when added to food, rapamycin exhibited the greatest geroprotective effect than in young mice (Wilkinson et al. 2012). The beneficial effects of chokeberry extracts have been revealed in different in vitro and in vivo models and at different levels from the cellular (Abdullah Thani et al. 2012; Cvetanović et al. 2018; Parzonko et al. 2015; Valdez et al. 2020) before organismic (Makanae et al. 2019).

The purpose of this work was to reveal the lifespan effects induced by ABE treatment at different ages. To assess whether the geroprotective effects of ABE can be affected by the age of treatment we supplemented Aronia extract to the Drosophila imago throughout life, during the ages of 1-2 weeks and 4-6 weeks of life, that correspond to young and average ages, respectively. We studied the effects of $\mathrm{ABE}$ treatment at different ages and concentrations on the healthspan (locomotor activity, intestinal integrity) and stress resistance. The maximum beneficial effect on lifespan was found for $\mathrm{ABE}$ treatment at the age of $4-6$ weeks $(3-9 \%)$. The performed RT-PCR assay revealed the effects of ABE on the age-related changes in the expression level of stress response genes. The $\mathrm{ABE}$ supplementation has increased expression of heat shock proteins (Hsp27, Hsp68, Hsp83), oxidative stress resistance genes (Keapl, NRF, Sodl), circadian clock genes (Clk, per) and gene of longevity Sirt1 thereby increases resistance to oxidative stress and hyperthermia, but 
with age the expression of genes Per, Sirt1 and Keapl has decreased. Therefore, ABE shows that different dietary schemes extended lifespan and resistance to different stress.

\section{Material and methods}

\section{Extraction}

Aronia berries were harvested in the autumn period (August - September), on the territory of the Komi Republic (Northwest Russia). The berries were pre-frozen at a temperature of - $20^{\circ}$ C. To prepare the extract, the fruits were crushed and centrifuged to obtain a supernatant. This mass was mixed with clay ( 0.1 molar hydrochloric acid solution) and centrifuged again. The resulting liquid was poured off and mixed with the extractant: $1 \%$ solution of concentrated hydrochloric acid in $96 \%$ ethanol. The resulting solution was centrifuged, and then ethanol from the extract was evaporated on an IR-1M vacuum rotary evaporator (Khimlaborpribor, Russia) at $35^{\circ} \mathrm{C}$. The experimental concentrations of Aronia berry extract (ABE) were prepared from the obtained ethanol extract by dilution in $96 \%$ ethanol.

High performance liquid chromatography (HPLC)

ABE samples were analyzed on a Thermo Finnigan liquid chromatograph (Thermo Fisher Scientific Inc., USA) using a diode array detector $(200-600 \mathrm{~nm})$ in tandem with a mass selective detector of the same company. The analysis was carried out at a wavelength of 520 $\mathrm{nm}$, an eluent feed rate of $1 \mathrm{ml} / \mathrm{min}$, analysis time of 40 minutes, in isocratic mode. The eluent acetonitrile - an aqueous solution of formic acid (10\%) in the ratio of 7:93 (v/v) was used in the analysis). Column $4 \times 250 \mathrm{~mm}$ with a sorbent Diasorb-130-C16T, granulation 7 $\mu \mathrm{m}$.

For sample preparation $1 \mathrm{mg}$ of the extract was dissolved in $10 \mathrm{ml}$ of deionized water, after which it was applied to a prepared cartridge with the Hypersep C18 sorbent. The cartridge with the applied extract was washed with $10 \mathrm{ml}$ of deionized water, then the target substances were washed off the cartridge with $1 \mathrm{ml}$ of eluent (acetonitrile - aqueous formic acid solution $(10 \%)$ in the ratio of $7: 93(\mathrm{v} / \mathrm{v})$. The sample thus prepared was analyzed by High Performance Liquid Chromatography-Mass Spectrometry (HPLC-MS).

\section{Drosophila rearing}

D. melanogaster wild type Canton-S line was obtained from Bloomington Stock Center at Indiana University (\#64349, Bloomington, USA). The flies were maintained at $25^{\circ} \mathrm{C}$ and at 
$60 \%$ relative humidity under a $12 \mathrm{~h}: 12 \mathrm{~h}$ light/dark cycle in a constant climate chamber Binder KBF720-ICH (Binder, Germany). The food media on which the flies lived contained water - $1000 \mathrm{ml}$, corn flour - $92 \mathrm{~g}$, dry yeast - $32.1 \mathrm{~g}$, agar-agar - $5.2 \mathrm{~g}$, glucose - $136.9 \mathrm{~g}$ (Xia B et al. 2016) to which $5 \mathrm{ml}$ of a $10 \%$ solution of nipagin in ethanol, and $5 \mathrm{ml}$ of propionic acid were added.

Treatment with Aronia berry extract

For imago feeding, ABE extracts $(0.01 ; 0.1 ; 1.0 ; 2.5 ; 5.0$ and $10 \mathrm{mg} / \mathrm{ml})$ were directly added to the surface of the fresh medium ( $30 \mu \mathrm{l}$ per vial). The $30 \mu 196 \%$ ethanol was added to the medium surface of control vials. Vials were dried under a fan.

\section{Ages of ABE treatment}

We treated flies with $\mathrm{ABE}$ at different imago ages. The first group received the extract throughout its life. The second group was treated at the age of 1-2 weeks old and the third group - at the age of 4-6 weeks old. The second and third groups, before and after the addition of the $\mathrm{ABE}$, respectively, were fed with control medium. The experiments were carried out in 3 replicates.

\section{Lifespan analysis}

After imago hatching, flies were anastezied using $\mathrm{CO}_{2}$, separated by sex, and transferred in vials containing the nutrient medium with investigated drugs (30 flies per vial) and the lifespan was assessed by recording the age of spontaneous death of flies. Dead flies were counted daily, and the remaining live flies were placed in new vials of fresh medium twice a week. The median and maximum (age 90\% mortality) life expectancy and mortality doubling time (MRDT) were calculated.

\section{Stress resistance analysis}

To investigate the effect of $\mathrm{ABE}$ feeding on the resistance to oxidative stress, starvation and hyperthermia, the newly enclosed male and female flies were collected and fed a diet with or without the ABE for 14 days and 33 days. The experimental flies were reared on the nutrient medium with $\mathrm{ABE}$ in concentrations $0.1,1.0$ and $5.0 \mathrm{mg} / \mathrm{ml}$. To assay resistance to oxidative stress, flies were exposed to medium composed of $2 \%$ agar, $5 \%$ sucrose and $20 \mathrm{mM}$ paraquat (Sigma-Aldrich, USA). During starvation the flies were kept on $2 \%$ agar medium. Hyperthermia was induced by continuous exposure of the flies to $35^{\circ} \mathrm{C}$. Dead flies were 
identified using the DAM2 Drosophila Activity Monitor (TriKinetics Inc., USA) by the complete absence of movement. In each experimental variant 32 flies of each sex were analyzed. All experiments were carried out in two replicates.

Analysis of locomotor activity

The age-dependent changes in spontaneous locomotor activity was measured using the LAM25 Locomotor Activity Monitor (TriKinetics Inc., USA) under standard $12 \mathrm{~h}$ lights on, $12 \mathrm{~h}$ lights off conditions. The data from 10 flies in 4 vials as replicates were collected during $24 \mathrm{~h}$ and represented as average total daily locomotor activity. Measurements were carried out every week, from the age of 1 to 9 weeks. The experimental flies were contained on the nutrient medium with $\mathrm{ABE}$ in concentrations 0.1, 1.0 and $5.0 \mathrm{mg} / \mathrm{ml}$.

Analysis of intestinal integrity

The Smurf assay was used for intestinal barrier permeability estimation (Rera et al. 2012). The flies from both control and experimental cohorts were tested at ages of 2, 6 and 8 weeks. Both cohorts were kept during 16 hours on a food medium containing 2.5\% (mass/volume) blue food dye (Brilliant Blue FCF) after that the flies were transferred to the standard medium. The induction of "Smurf"-phenotype detecting intestinal permeability increase was accounted for in the sample if only the whole fly was dyed blue. The experimental flies were contained on the nutrient medium with $\mathrm{ABE}$ in concentrations $0.01 ; 0.1 ; 1.0 ; 2.5 ; 5.0$ and 10 $\mathrm{mg} / \mathrm{ml}$.

Analysis of Food choice (FLIC assay)

Time-dependent changes in food preference were analyzed using flies at the age of 7 and 45 day old from the control and ABE-treated groups. A fly liquid - food interaction counter (FLIC) system (Sable Systems, USA) was used to analyze feeding behavior as described (Ro et al. 2014). For food choice assay each channel of Drosophila Feeding Monitor (DFM) was loaded with either $5 \%$ sucrose $(-\mathrm{ABE}$ control) or $30 \mu \mathrm{l} / \mathrm{ml} \mathrm{ABE}$ in $5 \%$ sucrose (+ABE experiment). Before the assay, flies were starved in Drosophila vial without medium during $2 \mathrm{~h} 30 \mathrm{~m}$. The assay was performed for $3 \mathrm{hr}$ using 6 flies. FLIC Monitor Software (downloaded from flidea.tech) was used to collect raw data from the DFM. Feeding Preference Index (PI) values from the FLIC system were calculated as the difference in total feeding time between the control and experimental foods divided by total feeding time for 
both foods (Ro et al. 2014). The PI ranged from 1 (complete preference for $-\mathrm{ABE}$ control food) to -1 (complete preference for $+\mathrm{ABE}$ experimental food) with a value of 0 indicating no food preference. PI value was calculated for each individual fly and presented as mean PIs for the experimental groups.

Quantitative real time PCR

For each variant of the experiment, 30 males and females were selected per test tube (Genesee Scientific, USA) on the nutrient medium with ABE in concentrations 0.1, 1 and 5 $\mathrm{mg} / \mathrm{ml}$. Males and females lived separately at $25{ }^{\circ} \mathrm{C}$ under 12-hour lighting in Binder KBF720-ICH climatic chambers (Binder, Germany). The analysis was performed at the age of 14 and 33 days. For each variant of the experiment, 20 males and 10 females were selected. The experiment was carried out in three biological replicates, with three analytical replicates inside each.

Gene expression was measured by quantitative real-time PCR with a reverse transcription step. RNA was isolated using an Aurum Total RNA mini kit (Bio-Rad, USA) according to the manufacturer's instructions. RNA concentration was measured using a Quant-iT RNA Assay Kit (Invitrogen, USA) according to the manufacturer's instructions. cDNA was synthesized according to the iScript cDNA Synthesis Kit (Bio-Rad, USA) from the resulting RNA solution. The reaction mixture for the PCR reaction was prepared according to the instructions for iTaq Universal SYBR Green Supermix (Bio-Rad, USA) and primers (Supplementary Table S5). The primer design was performed using QuantPrime online tool (Arvidsson et al. 2008). The polymerase chain reaction was carried out using primers (Supplementary Table S5) in a CFX96 amplifier (Bio-Rad, USA) using the following program: 1) $95^{\circ} \mathrm{C}$ for $\left.30 \mathrm{~s}, 2\right) 95^{\circ} \mathrm{C}$ for $\left.10 \mathrm{~s}, 3\right) 60^{\circ} \mathrm{C}$ for $\left.30 \mathrm{~s}, 4\right)$ steps $2-3$ were repeated 49 times 5) DNA melting step.

The expression of the studied genes was calculated relative to the expression of the housekeeping genes Tubulin, eEF1 22 , RpL32 using the CFX Manager 3.1 software (BioRad, USA). Differences were considered significant changes (increase or decrease) in expression: $\mathrm{p}<0.05$ according to the Student's t-test and crossing the Regulation Threshold.

\section{Statistical analysis}

To compare the statistical differences in survival functions and median lifespan between control and experimental groups, the modified Kolmogorov-Smirnov and log-rank test were 
used, respectively (Fleming et al. 1980; Mantel 1966). A Wang-Allison test was used to estimate the differences in the age of $90 \%$ mortality (Wang et al. 2004a). To assess the statistical significance of differences in resistance to stress factors, the Fisher's exact test was used (Mehta et al. 1984). A Mann Whitney U-test was used for pairwise comparisons of feeding preference indexes (PMID: 11509435). Statistical analyses of the data were performed using STATISTICA software, version 6.1 (StatSoft, USA), R, version 2.15.1 (The R Foundation) and OASIS 2 (Online Application for Survival Analysis 2) (Han et al. 2016). $\mathrm{R}$ code for simple FLIC analyses Version 4.0 was used to analyze the signal data from FLIC DFMs (https://github.com/PletcherLab/FLIC_R_Code) (Ro et al. 2014).

\section{Results}

Chemical analysis of berry extracts

To determine the active substances in the ethanol extract of chokeberry, an HPLC method was required, which was carried out at a wavelength of $520 \mathrm{~nm}$, an eluent flow rate of 1 $\mathrm{ml} / \mathrm{min}$ and an analysis time of 40 minutes in an isocratic mode (Fig 1).

The chromatogram (Fig 1) shows the main jumps: at 10.54 min - delphinidin (Glu), 13.38 min - delphinidin (Rut), 16.64 min - cyanidin (Glu), which indicates that these substances are the main ones in the analyzed extract. Delphinidin and cyanidin are anthocyanidins, they are found in many bright blue-red fruits and berries, such as Manitoba berries, Saskatoon berry (Hosseinian and Beta 2007), eggplant (Sigurdson et al. 2018), more delphinidin will be collected. Cyanidin is the most common in raspberries, strawberries (Hosseinian and Beta 2007), and black chokeberry (Jurikova et al. 2017), sour cherry (Ertan et al. 2018) in apple skin (Ban et al. 2009), acai (Yamaguchi et al. 2015).

Unlike other fruits and berries, aronia fruits can contain a wide range of biologically active compounds, such as polyphenols: phenolic acids, flavonoids, anthocyanins, proanthocyanidins in various proportions (Tolić et al. 2015). This largely depends on the time of collection, on soil factors, climatic conditions, as well as on the extraction method (water, acetone, ethanol, water-ethanol) (Cvetanović et al. 2018; Hudec et al. 2006; Jurikova et al. 2017; Kokotkiewicz et al. 2010) 
The effects of treatment with Aronia berry extract $(\mathrm{ABE})$ at different ages of the imago The aging is associated with multiple physiological disorders. While reproductive potential and locomotor activity decrease, the inflammatory reactions and pathological processes increase (Flatt 2020; He and Jasper 2014b). Thereby the effect of geroprotective intervention may depend on the age of the organism. To reveal the connection between the geroprotective effect and age we studied the lifespan effects of ABE when imago flies were treated at different ages. In addition, it is necessary to take into account the characteristics of the periodization of the fly's life cycle, during which the most important changes in the body occur: reproductive maturation (the first days of life), then reproductive activity, then a decrease in reproductive activity and further death (Flatt 2020). Therefore, we chose different treatment ages, namely: (1) throughout life, (2) at the age of $1-2$ and (3) $4-6$ weeks at different concentrations $(0.01 ; 0,1 ; 1.0 ; 2.5 ; 5.0$ and $10 \mathrm{mg} / \mathrm{ml})$.

It was revealed that the ethanol extract from the fruits of chokeberry in concentrations: 0.01 ; $0.1 ; 1.0 ; 2.5 ; 5.0$ and $10.0 \mathrm{mg} / \mathrm{ml}$, supplied with food throughout life, negatively affects the median and the maximum lifespan (LS) of male (see Fig. 2A, B) and female (see Fig. 3A, B) Drosophila melanogaster (Supplementary Table S1). When the extract was added to food for $1-2$ weeks of adult life, $2.5 \mathrm{mg} / \mathrm{ml}$ in males (Fig. 2C, D) slightly increased the median lifespan (by 3\%), and in females (Fig. 3C, D) $10.0 \mathrm{mg} / \mathrm{ml}$ reduced the median LS of fruit flies by 9\% (Supplementary Table S2). Adding the extract to food at 4-6 weeks of adult life in males (Fig. 2E, F) increased the median lifespan by 5\%, and the maximum LS was increased by $9 \%$ at concentrations of 0.1 and $5.0 \mathrm{mg} / \mathrm{ml}$. In females (Fig. 3E, F), 0.1 and $5.0 \mathrm{mg} / \mathrm{ml}$ prolonged the median lifespan by $5 \%$, and all concentrations except $10.0 \mathrm{mg} / \mathrm{ml}$ increased the maximum lifespan of fruit flies by 3\% (Supplementary Table S3). Based on the data obtained, the use of the extract in middle age (4-6 weeks of life) has the greatest effect in increasing the lifespan in Drosophila melanogaster than its use throughout life and in the first weeks of life.

Previously, the effect of berry extracts used throughout the life of an imago on the model organism of Drosophila melanogaster was studied. Powder extract from bilberry (2.0 and 5.0 $\mathrm{mg} / \mathrm{ml}$ ) increased the average lifespan by $10 \%$ in Drosophila melanogaster (Peng et al. 2012) Acetone extract of cloudberries $(0.12 \mathrm{mg} / \mathrm{ml})$ in females caused an increase in median lifespan by $11 \%$ (Lashmanova et al. 2019). Polyphenol-rich apples increased average lifespan by $10 \%$ (Peng et al. 2011). Anthocyanin extract of cranberry $(20 \mathrm{mg} / \mathrm{ml})$ also increased the average lifespan of males by $10 \%$ (Wang et al. 2015). In an experiment with a mouse model with various age-related pathologies, individuals at the age of $20-22$ months received doses 
of rapamycin with food. In the group of mice receiving rapamycin, it showed a geroprotective effect, namely, reduced the risk of developing age-related diseases (changes in the liver, heart, adrenal glands) compared with the control group (Wilkinson et al. 2012)

In our experiments, we confirmed that to increase the lifespan of Drosophila melanogaster, a short intervention is enough even in old age. And when the extract is used throughout life, it has a negative effect, perhaps this is due to the extraction method and its contents.

\section{Locomotor activity}

Aging is associated with a decrease in the functionality of the whole organism and in particular the locomotor function (Wang et al. 2014b). Therefore, to reveal the potential efficiency of chokeberry extract to delay the functional aging of flies, we investigated the effect of the most effective geroprotective concentrations $(0.1 ; 1.0$ and $5 \mathrm{mg} / \mathrm{ml})$ on the agerelated changes of locomotor activity in Drosophila melanogaster.

No statistically significant differences in locomotor activity under the influence of chokeberry extract were revealed in males (Fig. 4A). However, in females (see Fig. 4B) 5 $\mathrm{mg} / \mathrm{ml} \mathrm{ABE}$ was the most effective concentration, which increased their locomotor activity at the age of 4 weeks old. At the same time, no harmful effects of ABE on locomotor activity as an indicator of the health of flies were found.

One of the previous studies showed that Aronia supplement at a concentration of $2.5 \mathrm{mg} / \mathrm{ml}$ also useful for maintaining locomotor activity in male flies (Jo and Imm 2017). This suggests that Aronia supplement may increase not only lifespan, but healthspan also. However, in several other works, berry supplements had no effect on locomotor activity in rats (Eftimov and Valcheva-Kuzmanova 2018; Fernández-Demeneghi et al. 2019; Janšakova et al. 2016; Valcheva-Kuzmanova et al. 2014; Valcheva-Kuzmanova and Zhelyazkova-Savova 2009) (Pomatto et al. 2017). So the question has been raised, what exactly is the mechanism of influence on locomotor activity by berries? The posed question needs to be verified by other methods.

\section{The Smurf assay}

Under the influence of external (changes in diet and lifestyle) and internal (various diseases) factors, the permeability of the intestinal barrier decreases (an increase in the number of inflammatory reactions and a decrease in the protective function) which negatively affects the health and quality of life of the body, especially with age. That is, by improving the functions 
of the intestinal barrier, namely its permeability, it is possible to reduce the number of agedependent diseases and increase lifespan (Bischoff et al. 2014; Rera et al. 2012; Vancamelbeke and Vermeire 2017). We have studied the effect of ABE on the Drosophila intestinal barrier permeability at the age of 2, 6 and 8 weeks old (Supplementary Table S4). At the age of 2 weeks, flies with the "Smurf" phenotype were not found. But at the age of 6 weeks flies and 8 weeks with the "Smurf" phenotype were identified. This suggests that with age, the functioning of a living organization decreases, including a violation of the integrity of the intestine, which in the future can lead to the death of the organism (Rera et al. 2012). But, no significant changes in males and females were found at 2, 6 and 8 weeks of life, which suggests that the ethanol extract of chokeberry with concentrations of $0.01 ; 0.1 ; 1.0$; 2.5; 5.0 and $10.0 \mathrm{mg} / \mathrm{ml}$ had no negative effect on the permeability of the intestinal barrier. Previously the effect of various chokeberry extracts on gastric permeability has been studied. Valdez et al, shows that aronia polyphenolic powder improved $(0.5-10 \mathrm{mg} / \mathrm{ml})$ barrier function of inflamed Caco-2 cells (Valdez et al. 2020). Olejnik et al, in vitro experiments on Caco-2 cells, using the Sambucus nigra L. fruit extract passing through the gastric tract, had an anti-inflammatory effect (Olejnik et al. 2016). Paulrayer et al found a gastroprotective effect in rats at a concentration of $200 \mathrm{mg} / \mathrm{kg}$ of an aqueous alcoholic extract of chokeberry (Paulrayer et al. 2017). From the above studies, it can be assumed that chokeberry extracts have a protective effect on the gastrointestinal tract, which is directly related to the quality of health, which ultimately can reduce age-related diseases (chronic inflammation, metabolic syndrome, insulin resistance) (Rera et al. 2012). Further study is needed of the effects of chokeberry extract, with a possible decrease in concentration, on the permeability of the intestinal barrier in Drosophila melanogaster.

\section{Food choice (FLIC assay)}

The high levels of phenolic compounds in Aronia may contribute to pronounced bitterness, sourness and astringency of ABE containing food media (Duffy et al. 2016; Sidor and Gramza-Michałowska 2019) and influence the feeding rate (Ro et al. 2014). Both reduced or excessive food consumption may affect nutritional status, health, and finally the lifespan (Tatar et al. 2014; Wong et al. 2009). To find out how ABE supplementation affects the food consumption we studied dietary preferences of flies at different ages using the FLIC system (Ro et al. 2014). In addition we revealed the possible effect of habituation to chokeberry 
flavor by analyzing feeding behaviour in flies that were kept either on control media or on media with $\mathrm{ABE}$ before the test.

The obtained results reflect the lack of strong preference (mean PI varies in wide ranges) of the males $(0.01 \mathrm{mg} / \mathrm{ml} \mathrm{ABE})$ and females $(0.01,2.5$, and $10 \mathrm{mg} / \mathrm{ml} \mathrm{ABE})$ for $-\mathrm{ABE}$ or $+\mathrm{ABE}$ food medium (Fig. 5). This data confirms the results of a previous study that demonstrated no significant difference in food intake between flies from control and supplemented with 2.5 $\mathrm{mg} / \mathrm{ml}$ aronia acetone extract groups estimated by gustatory assay (Jo and Imm 2017) demonstrating that the observed effects on lifespan and on healthspan are not associated with changes in food consumption. At the same time males of all groups exhibited weak preference (mean PI 0.2) in favor of control (-ABE) medium over $10 \mathrm{mg} / \mathrm{ml} \mathrm{ABE} \mathrm{(Fig.} \mathrm{5E),}$ suggesting that at high concentrations, the intense taste of chokeberry extract can lead to reduced food intake and induce dietary restriction-mediated effects. Control and $\mathrm{ABE}$ pretreated 7 days old males exhibited statistically significant $(\mathrm{p}<0.05)$ weak preference (mean $\mathrm{PI}-0.3$ ) in favor of $2.5 \mathrm{mg} / \mathrm{ml} \mathrm{ABE}$ media compared to 45 days old males (Fig. 5C). These age-related changes in food preference may partly explain the differences in lifespan effects of $\mathrm{ABE}$ related to feeding at different ages.

\section{Stress resistance}

The mechanisms of resistance to stress and longevity are interrelated (Saunders and Verdin 2009). Oxidative stress, which leads to disruption of redox homeostasis, is one of the important factors of aging and the organism's ability to respond to oxidative stress plays an important role in longevity (Kuether and Arking 1999). Treatment of flies with paraquat, high temperature and starvation may be a cause of free radicals, which in the future can lead to pathological processes in the body and further death (Nordquist et al. 1995; Robinson et al. 1997; Turrens 2003). In addition decreased stress tolerance is one of the manifestations of aging (Ikeyama et al. 2002; Pandolf 1997). Therefore, we were interested in how the aronia extract will affect the resistance of Drosophila melanogaster to various stresses (oxidative, hyperthermia and starvation) at the age of 14 and 33 days old (see Fig. 6). In these assays we used the extract at concentrations of $0.1 ; 1.0$ and $5.0 \mathrm{mg} / \mathrm{ml}$, that demonstrated the most effective geroprotective potential.

According to our data, in males (Fig. 6A), $1.0 \mathrm{mg} / \mathrm{ml} \mathrm{ABE}$ increased resistance to oxidative stress at 33 days of life but significantly reduced resistance to starvation at 14 days (Fig. 6C). And 0.1 and $5.0 \mathrm{mg} / \mathrm{ml} \mathrm{ABE}$ significantly increased the resistance of males to hyperthermia 
(Fig. 6E) on the 14th day of imago life. In females, $5 \mathrm{mg} / \mathrm{ml} \mathrm{ABE} \mathrm{had} \mathrm{a} \mathrm{protective} \mathrm{effect}$ against oxidative stress at 33 days of age (Fig. 6B), as well as starvation at 14 days of age in flies (Fig. 6D). On the 14th day of females' life, 0.1 and $5.0 \mathrm{mg} / \mathrm{ml}$ ABE increased resistance to hyperthermia, but on the 33rd day, all concentrations had a negative effect on resistance to hyperthermia (Fig. 6F). It is well known, Keapl suppresses transcription activity of $N r f 2$ (Jaramillo and Zhang 2013). Keap1/NRF2 signaling protects the body from oxidative stress, including aging-related diseases (Cheng et al. 2016; Li et al. 2019; Martel et al. 2019; Sykiotis and Bohmann 2008). We have shown an increase the resistance to oxidative stress of Drosophila at 14 and 33 days after treatment with ABE, perhaps it is due to the activation of $N r f 2$ and the subsequent decrease in the level of expression of Keapl. At the same time, Aronia extract did not significantly affect the resistance of flies to starvation, a similar effect was shown on cloudberries (Lashmanova et al. 2018).

Findings on the effect of $\mathrm{ABE}$ on the resistance to hyperthermia, it can be concluded that when Aronia extract is obtained for 14 days, both males and females, stress resistance increases, but already on day 33 their stress resistance decreases in both males and females. Perhaps due to prolonged and/or intake of high doses, flavonoids begin to act as mutagens, prooxidants, thereby aggravating their quality of life (Skibola and Smith 2000).

\section{RT-PCR}

Changes in gene expression levels are associated with the health and lifespan (Tyshkovskiy et al. 2019). Plant extracts have a wide range of pharmacological effects, which at the molecular level are determined by the effects on the transcriptional activity of genes, including stress response genes. Thus, we have studied the changes in expression level of cellular stress response genes, including heat shock proteins (Hsp27, Hsp68, Hsp83), oxidative stress resistance genes (Keapl, NRF, Sodl, HIFl) and circadian clock genes (Clk, per) gene of longevity Sirtl. The mRNA expression level was identified by RT-PCR on 14 (Supplementary Table S6) and 33 (Supplementary Table S7) days of the life. The effects of $0.1 ; 1.0$ and $5.0 \mathrm{mg} / \mathrm{ml}$ of chokeberry extract were analyzed (see Fig.7).

It was revealed that in males at the age of 33 days old (Fig. 7C) $0.1 \mathrm{mg} / \mathrm{ml}$ of ABE increased the expression of $C l k$ gene, while the transcriptional activity of per gene decreased. At the same time, females exhibited increased expression of per at concentrations of 0.1 and 5.0 $\mathrm{mg} / \mathrm{ml}$. And also on the 33rd day of life, there was a slight increase in $C l k$ expression level at all $\mathrm{ABE}$ concentrations used. At the age of 14 days old, males (Fig. 7A) had a pronounced 
increase in the expression of oxidative stress resistance genes such as Keapl $(0.1 \mathrm{mg} / \mathrm{ml})$ and sirt1 $(1.0 \mathrm{mg} / \mathrm{ml})$ and the expression of these genes decreased with age. In females of different ages, the changes in the expression level of the most studied genes were not significant, except for Keapl, which demonstrated the increase of the expression level after supplementation with $0.1 \mathrm{mg} / \mathrm{ml}$ of ABE on day 14. With age (33 days of life) (see Fig. 7C), an increase in the expression level of Hsp68 was caused by 0.1 . In females, on the 14th day of life (Fig. 7B), an increase in the expression level of the $H s p 83$ gene was observed at 0.1 $\mathrm{mg} / \mathrm{ml}$ of $\mathrm{ABE}$, at the same time, on the 33rd day of life (Fig. 7D), there was more pronounced increase in the expression level of $H s p 27$ at $0.1 \mathrm{mg} / \mathrm{ml}$ than other concentrations. With age, females show a general increase in the expression level of genes encoding heat shock proteins.

We demonstrated that the Aronia extract increased expression of the sirtl gene that previously showed to be involved in cellular stress defense mechanisms such as protection against oxidative stress, DNA repair and may contribute to decrease in risk of various agerelated disorders (Elibol and Kilic 2018; Kayashima et al. 2017). The heat shock proteins (HSP) is one of the systems of cellular defense in response to various stress conditions. Increased expression of HSP genes such as Hsp27, Hsp68 and Hsp83 may increase resistance to paraquat and starvation (Wang et al. 2004b). It has been shown that Hsps are involved in acquired resistance to stress (hormesis), such hormesis correlates with increased Hsp expression and may lead to a slight increase in lifespan (Tower 2011). Our data on increased expression of heat shock proteins genes also show a connection with these statements. It should be noted that the effects of HSPs overexpression on longevity are ambiguous. For example overexpression of $h s p 70$ in the nervous system and muscles or RNAi-mediated down-regulation of $h s p 70$ had shown no effect on Drosophila longevity while ubiquitous overexpression reduced the lifespan of males (Xiao et al. 2019).

The treatment of cells with anthocyanin-rich extract of Aronia melanocarpa shown to increase the level of $\mathrm{Nrf} 2$ in a concentration-dependent manner. The extract increased activation of Nrf2 approximately 4.5 times in a concentration of $25 \mu \mathrm{g} / \mathrm{ml}$ in comparison with angiotensin II treated cells (Parzonko et al. 2015). Treatment of a glioblastoma cell line (U373) with an extract of chokeberry (Aronia melanocarpa) and curcumin (Curcuma longa), for 48 hours, caused a decrease in the expression of the MMP-2, -14, -16 and -17 genes(Abdullah Thani et al. 2012). The extract of chokeberry (2.9 g/kg of body weight) supplementation with food and further exercise increased the activity of mTORC1 in rats 
(Makanae et al. 2019). The the positive effect on lifespan has been reported to be associated with increased expression of SOD, CAT, GPX genes and suppression of the MTH gene (Jo and Imm 2017; Lashmanova et al. 2019; Peng et al. 2011; Peng et al. 2012; Wang et al. 2015). Antioxidant activity (decrease in the level of Sod2, Gpx1 and Prdx1) of 4.5\% lyophilized powder of chokeberry berries was also revealed in the colon and mesenteric lymph node (Pei et al. 2019a; Pei et al. 2019b). Ethanol extract of chokeberry has been shown to inhibit hydrogen peroxide-induced ROS production in murine macrophage cell culture in a dose-dependent manner and exhibit strong radical scavenging activity (Ghosh et al. 2018)

\section{Discussion}

In this study, we found that the extract of chokeberry in small concentrations and for a limited period of time (in our case, two weeks), increases lifespan, which means it corresponds to the idea that chokeberry may be hormetin. In addition, it was found that the black chokeberry extract meets the main criteria of a geroprotector: it is not toxic and does not exhibit toxic properties, it increases the lifespan of the model organism and improves the quality of life. $\mathrm{ABE}$ also meets the secondary criteria: it increases resistance to environmental stressors and has prophylactic properties against age-related diseases (Moskalev et al. 2016). Based on this, we can assume that hormetins are geroprotectors.

The interest of society in improving the quality of life and possible longevity is growing every year, and this is possible due to the reduction of age-related diseases (inflammatory processes in the organism) (Jurikova et al. 2017; Kokotkiewicz et al. 2010; StaszowskaKarkut and Materska 2020). Based on the traditional medicine, we can assume that by supplementing our diet with natural products (berries, fruits and vegetables), we can significantly improve the health of our organism with age (Belwal et al. 2017; Kokotkiewicz et al. 2010; Kristo et al. 2016; Prior 2010) Besides, with age dietary needs change, especially which nutrients are important and needed for an aging organism (Institute of Medicine Food 2010). As mentioned earlier, a plant-based diet containing substances such as polyphenols, flavonoids, and anthocyanins may have positive effects on lifespan and also can help with anti-aging diseases. However, the amount and timing of nutrient intake are equally important. The optimal effect of diet on aging and disease is usually associated with a narrow dose range. Excessive intake or deficiency of nutrients can have an adverse effect on the organism's health because the dose - response relationship is non-linear (Evangelakou et al. 2019; Skorupa et al. 2008). With regard to the period of nutrient intake, in old age the use of 
many nutrients becomes less efficient, therefore, their demand increases. It becomes necessary to add berries, fruits and vegetables to the diet, which contain large amounts of polyphenols, including anthocyanins. Anthocyanins produce a wide range of health benefits such as weight gain, anti-inflammatory, insulin resistance and regulation of immune function (Belwal et al. 2017; Ding et al. 2018; Prior 2010; Valenza et al. 2018). It is suggested that berries and fruits supplement to the diet may not only help reduce the risk of various diseases, such as cancer, cardiovascular, type 2 diabetes, but also improve the quality and longevity of life. (Basu et al. 2010; Calvano et al. 2019; Kalt et al. 2020; Kristo et al. 2016). Perhaps the anthocyanins that contained in Aronia may act as mild stress and activate protective mechanisms in cells.

The obtained data suggest that the most pronounced geroprotective effect of ABE observed when treatment was conducted at the age of 4-6 weeks relative to the other tested regimes (Institute of Medicine Food 2010). Namely, when ABE is used in middle age (4-6 weeks of life) and for a limited period of time (in our case, 2 weeks), the average life expectancy in males and females increases by $5 \%(0.1$ and $5.0 \mathrm{mg} / \mathrm{ml})$. The maximum lifespan of ABE $(0.01 ; 0.1 ; 2.5$ and $5.0 \mathrm{mg} / \mathrm{ml})$ increases by $3 \%$ in females, and in males by $9 \%(0.1$ and 5.0 $\mathrm{mg} / \mathrm{ml}$ ) Drosophila melanogaster. Other results are observed in females, perhaps this is due to sexual dimorphism. The study showed that genes are expressed differently depending on gender (Parisi et al. 2004). This is probably because females need more nutrients, due to sexual dimorphism, that is females experience constant energy costs for reproduction through continuous laying eggs (Camus et al. 2017; Wu et al. 2020). $0.1 \mathrm{mg} / \mathrm{ml}$ increases resistance to oxidative stress on the 33rd day of life of flies. In addition, $5.0 \mathrm{mg} / \mathrm{ml}$ is an effective dose for females with regard to locomotor activity, as well as to increase resistance to oxidative stress at 33 days of life, as well as hyperthermia and starvation at 14 days of age. Hormetic reactions associated with the $N r f 2$ / Keap pathway exhibit the geroprotective effect of ethanol extract of chokeberry berries. The same metabolic pathways and cellular processes are activated by polyphenols (Martel et al. 2019). Anthocyanins found in chokeberry fruits, may reduce ROS levels by activating NRF2 thereby inducing the expression of antioxidant enzymes (Belwal et al. 2017; Ding et al. 2018; Prior 2010; Valenza et al. 2018). The induced increase in the lifespan of Drosophila Aronia extract could be due to hormetic reactions.

\section{Conclusions}


According to our data, the ethanol extract of chokeberry in low concentrations and in a short time period manifests itself as hormetin, thereby showing the greatest geroprotective potential, on the life cycle of Drosophila melanogaster. In addition, it can be assumed that we have found the critical age for dietary intervention, when the addition of Aronia extract maximizes the median and maximum life expectancy. However, for such high-profile statements, more experiments are needed with different extracts and their reproducible results.

But, our result shows that black chokeberry extract contains various antioxidants that may positively affect the longevity of life. In addition, Aronia extract may increase the resistance of flies to hyperthermia and oxidative stress. Aronia extract may become one of the most dignified "weapons" in the fight against aging.

Author Contributions Conceptualization, EYP, MVS, AAM; Methodology, EYP, NVZ, MVS, VVP, SAP; Software, EYP, NVZ, MVS; Investigation, EYP, NVZ, MVS, DAG, DVK, NRM, NSU, VVP, SAP; Data Curation, EYP, NVZ, MVS; Writing - Original Draft Preparation, EYP, NVZ, MVS, DAG; Writing - Review \& Editing, AAM; Visualization, EYP, NVZ, MVS, SAP; Supervision, MVS, AAM; Project Administration, EYP, AAM; Funding Acquisition, AAM.

Funding This study was funded by RFBR and the National Research Foundation of Korea according to the research project № 19-515-51001.

Acknowledgments We are grateful to the Institute of Chemistry of Komi Science Center for assistance in the analysis of extract composition.

\section{Compliance with ethical standards}

Conflict of Interest The authors declare no conflict of interest.

\section{Electronic supplementary material}

Supplementary material 1 (PDF 257 kb) 


\section{References}

Abdullah Thani NA et al. (2012) Induction of apoptosis and reduction of MMP gene expression in the U373 cell line by polyphenolics in Aronia melanocarpa and by curcumin Oncol Rep 28:1435-1442 doi:10.3892/or.2012.1941

Arvidsson S, Kwasniewski M, Riaño-Pachón DM, Mueller-Roeber B (2008) QuantPrime--a flexible tool for reliable high-throughput primer design for quantitative PCR BMC Bioinformatics 9:465 doi:10.1186/1471-2105-9-465

Ban Y, Kondo S, Ubi BE, Honda C, Bessho H, Moriguchi T (2009) UDP-sugar biosynthetic pathway: contribution to cyanidin 3-galactoside biosynthesis in apple skin Planta 230:871-881 doi:10.1007/s00425-009-0993-4

Basu A, Rhone M, Lyons TJ (2010) Berries: emerging impact on cardiovascular health Nutr Rev 68:168-177 doi:10.1111/j.1753-4887.2010.00273.x

Beedholm R, Clark BF, Rattan SI (2004) Mild heat stress stimulates 20S proteasome and its $11 \mathrm{~S}$ activator in human fibroblasts undergoing aging in vitro Cell Stress Chaperones 9:49-57 doi:10.1379/475.1

Belwal T, Nabavi SF, Nabavi SM, Habtemariam S (2017) Dietary Anthocyanins and Insulin Resistance: When Food Becomes a Medicine Nutrients 9 doi:10.3390/nu9101111

Bischoff SC et al. (2014) Intestinal permeability--a new target for disease prevention and therapy BMC Gastroenterol 14:189 doi:10.1186/s12876-014-0189-7

Borowska S, Brzóska MM (2016) Chokeberries (Aronia melanocarpa) and Their Products as a Possible Means for the Prevention and Treatment of Noncommunicable Diseases and Unfavorable Health Effects Due to Exposure to Xenobiotics 15:982-1017 doi:10.1111/1541-4337.12221

Calabrese EJ, Blain R (2005) The occurrence of hormetic dose responses in the toxicological literature, the hormesis database: an overview Toxicol Appl Pharmacol 202:289-301 doi:10.1016/j.taap.2004.06.023

Calabrese EJ, Dhawan G, Kapoor R, Iavicoli I, Calabrese V (2015) What is hormesis and its relevance to healthy aging and longevity? 16:693-707 doi:10.1007/s10522-015-96010

Calvano A, Izuora K, Oh EC, Ebersole JL, Lyons TJ, Basu A (2019) Dietary berries, insulin resistance and type 2 diabetes: an overview of human feeding trials Food Funct 10:6227-6243 doi:10.1039/c9fo01426h

Camus MF, Fowler K, Piper MWD, Reuter M (2017) Sex and genotype effects on nutrientdependent fitness landscapes in Drosophila melanogaster Proc Biol Sci 284 doi:10.1098/rspb.2017.2237

Cheng D, Wu R, Guo Y, Kong AN (2016) Regulation of Keap1-Nrf2 signaling: The role of epigenetics Curr Opin Toxicol 1:134-138 doi:10.1016/j.cotox.2016.10.008

Cvetanović A et al. (2018) Comparative in vitro studies of the biological potential and chemical composition of stems, leaves and berries Aronia melanocarpa's extracts obtained by subcritical water extraction Food and Chemical Toxicology 121:458-466 doi:https://doi.org/10.1016/j.fct.2018.09.045

Ding S, Jiang H, Fang J (2018) Regulation of Immune Function by Polyphenols J Immunol Res 2018:1264074 doi:10.1155/2018/1264074

Duffy VB, Rawal S, Park J, Brand MH, Sharafi M, Bolling BW (2016) Characterizing and improving the sensory and hedonic responses to polyphenol-rich aronia berry juice Appetite 107:116-125 doi:10.1016/j.appet.2016.07.026

Eftimov MT, Valcheva-Kuzmanova S (2018) Investigation of Aronia Melanocarpa Fruit Juice for Sedative-Hypnotic Effects in Rats Journal of Biomedical and Clinical Research 11:77-82 doi:10.2478/jbcr-2018-0012 
Elibol B, Kilic U (2018) High Levels of SIRT1 Expression as a Protective Mechanism Against Disease-Related Conditions Front Endocrinol (Lausanne) 9:614 doi:10.3389/fendo.2018.00614

Ertan K, Türky1lmaz M, Özkan M (2018) Effect of sweeteners on anthocyanin stability and colour properties of sour cherry and strawberry nectars during storage J Food Sci Technol 55:4346-4355 doi:10.1007/s13197-018-3387-4

Evangelakou Z, Manola M, Gumeni S, Trougakos IP (2019) Nutrigenomics as a tool to study the impact of diet on aging and age-related diseases: the Drosophila approach Genes Nutr 14:12 doi:10.1186/s12263-019-0638-6

Fernández-Demeneghi R, Rodríguez-Landa J-F, Guzmán-Gerónimo R-I, Acosta-Mesa H-G, Meza-Alvarado E, Vargas-Moreno I, Herrera-Meza S (2019) Effect of blackberry juice (Rubus fruticosus L.) on anxiety-like behaviour in Wistar rats International Journal of Food Sciences and Nutrition 70:856-867 doi:10.1080/09637486.2019.1580680

Flatt T (2020) Life-History Evolution and the Genetics of Fitness Components in Drosophila melanogaster Genetics 214:3-48 doi:10.1534/genetics.119.300160

Fleming TR, O'Fallon JR, O'Brien PC, Harrington DP (1980) Modified KolmogorovSmirnov Test Procedures with Application to Arbitrarily Right-Censored Data Biometrics 36:607-625 doi:10.2307/2556114

Ghosh M et al. (2018) The Effects of Aronia melanocarpa 'Viking' Extracts in Attenuating RANKL-Induced Osteoclastic Differentiation by Inhibiting ROS Generation and cFOS/NFATc1 Signaling Molecules (Basel, Switzerland) 23:615 doi:10.3390/molecules23030615

Han SK et al. (2016) OASIS 2: online application for survival analysis 2 with features for the analysis of maximal lifespan and healthspan in aging research Oncotarget 7:5614756152 doi:10.18632/oncotarget.11269

He Y, Jasper H (2014a) Studying aging in Drosophila Methods 68:129-133 doi:10.1016/j.ymeth.2014.04.008

He Y, Jasper H (2014b) Studying aging in Drosophila Methods 68:129-133 doi:10.1016/j.ymeth.2014.04.008

Hosseinian FS, Beta T (2007) Saskatoon and wild blueberries have higher anthocyanin contents than other Manitoba berries J Agric Food Chem 55:10832-10838 doi:10.1021/jf072529m

Hudec J, Bakos D, Mravec D, Kobida L, Burdová M, Turianica I, Hlusek J (2006) Content of phenolic compounds and free polyamines in black chokeberry (Aronia melanocarpa) after application of polyamine biosynthesis regulators J Agric Food Chem 54:36253628 doi:10.1021/jf060299q

Ikeyama S, Kokkonen G, Shack S, Wang XT, Holbrook NJ (2002) Loss in oxidative stress tolerance with aging linked to reduced extracellular signal-regulated kinase and Akt kinase activities Faseb j 16:114-116 doi:10.1096/fj.01-0409fje

Institute of Medicine Food F (2010) The National Academies Collection: Reports funded by National Institutes of Health. In: Providing Healthy and Safe Foods As We Age: Workshop Summary. National Academies Press (US)

Copyright (C) 2010, National Academy of Sciences., Washington (DC). doi:10.17226/12967

Janšakova K, Babíčkova J, Havrlentova M, Hodosy J, Kraic J, Celec P, Tothova L (2016) The effects of anthocyanin-rich wheat diet on the oxidative status and behavior of rats Croat Med J 57:119-129 doi:10.3325/cmj.2016.57.119

Jaramillo MC, Zhang DD (2013) The emerging role of the Nrf2-Keap1 signaling pathway in cancer Genes Dev 27:2179-2191 doi:10.1101/gad.225680.113 
Jo AR, Imm JY (2017) Effects of aronia extract on lifespan and age-related oxidative stress in Drosophila melanogaster Food Sci Biotechnol 26:1399-1406 doi:10.1007/s10068017-0180-5

Jurikova T et al. (2017) Fruits of Black Chokeberry Aronia melanocarpa in the Prevention of Chronic Diseases Molecules 22 doi:10.3390/molecules22060944

Kalt W, Cassidy A, Howard LR, Krikorian R, Stull AJ, Tremblay F, Zamora-Ros R (2020) Recent Research on the Health Benefits of Blueberries and Their Anthocyanins Adv Nutr 11:224-236 doi:10.1093/advances/nmz065

Kayashima Y, Katayanagi Y, Tanaka K, Fukutomi R, Hiramoto S, Imai S (2017) Alkylresorcinols activate SIRT1 and delay ageing in Drosophila melanogaster Sci Rep 7:43679 doi:10.1038/srep43679

Kokotkiewicz A, Jaremicz Z, Luczkiewicz M (2010) Aronia plants: a review of traditional use, biological activities, and perspectives for modern medicine J Med Food 13:255269 doi:10.1089/jmf.2009.0062

Kristo AS, Klimis-Zacas D, Sikalidis AK (2016) Protective Role of Dietary Berries in Cancer Antioxidants (Basel) 5 doi:10.3390/antiox5040037

Kuether K, Arking R (1999) Drosophila selected for extended longevity are more sensitive to heat shock Age (Omaha) 22:175-180 doi:10.1007/s11357-999-0020-5

Lashmanova EA, Kuzivanova OA, Dymova OV, Moskalev AA (2018) [The effects of cloudberry extract on Drosophila melanogaster lifespan and stress resistance.] Adv Gerontol 31:958-965

Lashmanova EA, Kuzivanova OA, Dymova OV, Moskalev AA (2019) The Effects of Cloudberry Fruit Extract on Drosophila melanogaster Lifespan and Stress Resistance Advances in Gerontology 9:254-260 doi:10.1134/s2079057019020127

Li R, Jia Z, Zhu H (2019) Regulation of Nrf2 Signaling React Oxyg Species (Apex) 8:312322

Makanae Y, Ato S, Kido K, Fujita S (2019) Dietary Aronia melanocarpa extract enhances mTORC1 signaling, but has no effect on protein synthesis and protein breakdownrelated signaling, in response to resistance exercise in rat skeletal muscle J Int Soc Sports Nutr 16:60-60 doi:10.1186/s12970-019-0328-1

Mantel N (1966) Evaluation of survival data and two new rank order statistics arising in its consideration Cancer Chemother Rep 50:163-170

Markaki M, Tavernarakis N (2011) The role of autophagy in genetic pathways influencing ageing Biogerontology 12:377-386 doi:10.1007/s10522-011-9324-9

Martel J, Ojcius DM, Ko YF, Ke PY, Wu CY, Peng HH, Young JD (2019) Hormetic Effects of Phytochemicals on Health and Longevity Trends Endocrinol Metab 30:335-346 doi:10.1016/j.tem.2019.04.001

Mehta CR, Patel NR, Tsiatis AA (1984) Exact significance testing to establish treatment equivalence with ordered categorical data Biometrics 40:819-825

Moskalev A et al. (2016) Developing criteria for evaluation of geroprotectors as a key stage toward translation to the clinic Aging Cell 15:407-415 doi:10.1111/acel.12463

Nordquist RE, Nguyen H, Poyer JL, Carubelli R (1995) The role of free radicals in paraquatinduced corneal lesions Free Radic Res 23:61-71 doi:10.3109/10715769509064020

Olejnik A et al. (2016) Gastrointestinal digested Sambucus nigra L. fruit extract protects in vitro cultured human colon cells against oxidative stress Food Chem 197:648-657 doi:10.1016/j.foodchem.2015.11.017

Oszmiański J, Wojdylo A (2005) Aronia melanocarpa phenolics and their antioxidant activity 221:809-813 doi:10.1007/s00217-005-0002-5

Pandolf KB (1997) Aging and human heat tolerance Exp Aging Res 23:69-105 doi:10.1080/03610739708254027 
Parisi M et al. (2004) A survey of ovary-, testis-, and soma-biased gene expression in Drosophila melanogaster adults Genome Biol 5:R40 doi:10.1186/gb-2004-5-6-r40

Parzonko A, Oświt A, Bazylko A, Naruszewicz M (2015) Anthocyans-rich Aronia melanocarpa extract possesses ability to protect endothelial progenitor cells against angiotensin II induced dysfunction Phytomedicine 22:1238-1246 doi:10.1016/j.phymed.2015.10.009

Paulrayer A et al. (2017) Aronia melanocarpa (Black Chokeberry) Reduces Ethanol-Induced Gastric Damage via Regulation of HSP-70, NF-kB, and MCP-1 Signaling Int J Mol Sci 18 doi:10.3390/ijms 18061195

Pei R et al. (2019a) Aronia Berry Supplementation Mitigates Inflammation in T Cell Transfer-Induced Colitis by Decreasing Oxidative Stress Nutrients 11:1316 doi:10.3390/nu11061316

Pei R et al. (2019b) Aronia Berry Supplementation Mitigates Inflammation in $\mathrm{T}$ Cell Transfer-Induced Colitis by Decreasing Oxidative Stress Nutrients 11 doi:10.3390/nu11061316

Peng C, Chan HY, Huang Y, Yu H, Chen ZY (2011) Apple polyphenols extend the mean lifespan of Drosophila melanogaster J Agric Food Chem 59:2097-2106 doi:10.1021/jf1046267

Peng C et al. (2012) Blueberry extract prolongs lifespan of Drosophila melanogaster Exp Gerontol 47:170-178 doi:10.1016/j.exger.2011.12.001

Pietsch K, Saul N, Chakrabarti S, Stürzenbaum SR, Menzel R, Steinberg CE (2011) Hormetins, antioxidants and prooxidants: defining quercetin-, caffeic acid- and rosmarinic acid-mediated life extension in C. elegans Biogerontology 12:329-347 doi:10.1007/s10522-011-9334-7

Pomatto L, Wong S, Carney C, Shen B, Tower J, Davies K (2017) The age- and sex-specific decline of the 20s proteasome and the $\mathrm{Nrf} 2 / \mathrm{CncC}$ signal transduction pathway in adaption and resistance to oxidative stress in Drosophila melanogaster Aging doi:10.18632/aging.101218

Prior RL (2010) Anthocyanins and weight loss CAB Reviews: Perspectives in Agriculture, Veterinary Science, Nutrition and Natural Resources 5 doi:10.1079/PAVSNNR20105029

Proshkina E et al. (2020) Terpenoids as Potential Geroprotectors Antioxidants (Basel, Switzerland) 9:529 doi:10.3390/antiox9060529

Rattan S (2015) Hormetins as Novel Components of Cosmeceuticals and Aging Interventions Cosmetics 2:11-20 doi:10.3390/cosmetics2010011

Rattan SI (1996) Cellular and molecular determinants of ageing Indian J Exp Biol 34:1-6

Rattan SI (2000) Ageing, gerontogenes, and hormesis Indian J Exp Biol 38:1-5

Rattan SI (2004) Aging, anti-aging, and hormesis Mech Ageing Dev 125:285-289 doi:10.1016/j.mad.2004.01.006

Rattan SI (2008) Hormesis in aging Ageing Res Rev 7:63-78 doi:10.1016/j.arr.2007.03.002

Rera M, Clark RI, Walker DW (2012) Intestinal barrier dysfunction links metabolic and inflammatory markers of aging to death in Drosophila Proc Natl Acad Sci U S A 109:21528-21533 doi:10.1073/pnas. 1215849110

Ro J, Harvanek ZM, Pletcher SD (2014) FLIC: high-throughput, continuous analysis of feeding behaviors in Drosophila PLoS One 9:e101107 doi:10.1371/journal.pone.0101107

Robinson MK, Rustum RR, Chambers EA, Rounds JD, Wilmore DW, Jacobs DO (1997) Starvation enhances hepatic free radical release following endotoxemia J Surg Res 69:325-330 doi:10.1006/jsre.1997.5062 
Ryter SW, Choi AM (2013) Autophagy: An Integral Component of the Mammalian Stress Response J Biochem Pharmacol Res 1:176-188

Saunders LR, Verdin E (2009) Cell biology. Stress response and aging Science 323:10211022 doi: $10.1126 /$ science. 1170007

Sidor A, Gramza-Michałowska A (2019) Black Chokeberry Aronia melanocarpa L.-A Qualitative Composition, Phenolic Profile and Antioxidant Potential Molecules 24 doi:10.3390/molecules24203710

Sigurdson GT, Tang P, Giusti MM (2018) Cis-Trans Configuration of Coumaric Acid Acylation Affects the Spectral and Colorimetric Properties of Anthocyanins Molecules 23 doi:10.3390/molecules23030598

Skibola CF, Smith MT (2000) Potential health impacts of excessive flavonoid intake Free Radic Biol Med 29:375-383 doi:10.1016/s0891-5849(00)00304-X

Skorupa DA, Dervisefendic A, Zwiener J, Pletcher SD (2008) Dietary composition specifies consumption, obesity, and lifespan in Drosophila melanogaster Aging Cell 7:478-490 doi:10.1111/j.1474-9726.2008.00400.x

Staszowska-Karkut M, Materska M (2020) Phenolic Composition, Mineral Content, and Beneficial Bioactivities of Leaf Extracts from Black Currant (Ribes nigrum L.), Raspberry (Rubus idaeus), and Aronia (Aronia melanocarpa) Nutrients 12 doi:10.3390/nu12020463

Sykiotis GP, Bohmann D (2008) Keap1/Nrf2 signaling regulates oxidative stress tolerance and lifespan in Drosophila Dev Cell 14:76-85 doi:10.1016/j.devcel.2007.12.002

Taheri R, Connolly BA, Brand MH, Bolling BW (2013) Underutilized chokeberry (Aronia melanocarpa, Aronia arbutifolia, Aronia prunifolia) accessions are rich sources of anthocyanins, flavonoids, hydroxycinnamic acids, and proanthocyanidins $\mathrm{J}$ Agric Food Chem 61:8581-8588 doi:10.1021/jf402449q

Tatar M, Post S, Yu K (2014) Nutrient control of Drosophila longevity Trends Endocrinol Metab 25:509-517 doi:10.1016/j.tem.2014.02.006

Tolić M-T, Jurčević IL, Krbavčić IP, Marković K, Vahčić N (2015) Phenolic Content, Antioxidant Capacity and Quality of Chokeberry (Aronia melanocarpa) Products Food Technol Biotechnol 53:171-179 doi:10.17113/ftb.53.02.15.3833

Tower J (2011) Heat shock proteins and Drosophila aging Exp Gerontol 46:355-362 doi:10.1016/j.exger.2010.09.002

Turrens JF (2003) Mitochondrial formation of reactive oxygen species J Physiol 552:335-344 doi:10.1113/jphysiol.2003.049478

Tyshkovskiy A et al. (2019) Identification and Application of Gene Expression Signatures Associated with Lifespan Extension Cell Metabolism 30:573-593.e578 doi:10.1016/j.cmet.2019.06.018

Valcheva-Kuzmanova S, Eftimov M, Tashev R, Yankova L, Belcheva I, Belcheva S (2014) Effects of Aronia melanocarpa fruit juice on exploratory behaviour and locomotor activity in rats 43:315-323 doi:10.1556/aalim.43.2014.2.16

Valcheva-Kuzmanova S, Zhelyazkova-Savova M (2009) Anxiolytic-like effect of Aronia melanocarpa fruit juice in rats Methods Find Exp Clin Pharmacol 31:651-654 doi:10.1358/mf.2009.31.10.1423884

Valdez JC, Cho J, Bolling BW (2020) Aronia berry inhibits disruption of Caco-2 intestinal barrier function Archives of Biochemistry and Biophysics 688:108409 doi:https://doi.org/10.1016/j.abb.2020.108409

Valenza A, Bonfanti C, Pasini ME, Bellosta P (2018) Anthocyanins Function as AntiInflammatory Agents in a Drosophila Model for Adipose Tissue Macrophage Infiltration Biomed Res Int 2018:6413172 doi:10.1155/2018/6413172 
Van Beek JHGM, Kirkwood TBL, Bassingthwaighte JB (2016) Understanding the physiology of the ageing individual: computational modelling of changes in metabolism and endurance Interface Focus 6:20150079 doi:10.1098/rsfs.2015.0079

Vancamelbeke M, Vermeire S (2017) The intestinal barrier: a fundamental role in health and disease Expert Rev Gastroenterol Hepatol 11:821-834 doi:10.1080/17474124.2017.1343143

Verbeke P, Fonager J, Clark BF, Rattan SI (2001a) Heat shock response and ageing: mechanisms and applications Cell Biol Int 25:845-857 doi:10.1006/cbir.2001.0789

Verbeke P, Fonager J, Clark BFC, Rattan SIS (2001b) HEAT SHOCK RESPONSE AND AGEING: MECHANISMS AND APPLICATIONS Cell Biology International 25:845-857 doi:https://doi.org/10.1006/cbir.2001.0789

Wang C, Li Q, Redden DT, Weindruch R, Allison DB (2004a) Statistical methods for testing effects on "maximum lifespan" Mech Ageing Dev 125:629-632 doi:10.1016/j.mad.2004.07.003

Wang HD, Kazemi-Esfarjani P, Benzer S (2004b) Multiple-stress analysis for isolation of Drosophila longevity genes Proc Natl Acad Sci U S A 101:12610-12615 doi:10.1073/pnas.0404648101

Wang L, Karpac J, Jasper H (2014a) Promoting longevity by maintaining metabolic and proliferative homeostasis Journal of Experimental Biology 217:109-118 doi:10.1242/jeb.089920

Wang L, Karpac J, Jasper H (2014b) Promoting longevity by maintaining metabolic and proliferative homeostasis J Exp Biol 217:109-118 doi:10.1242/jeb.089920

Wang L, Li YM, Lei L, Liu Y, Wang X, Ma KY, Chen ZY (2015) Cranberry anthocyanin extract prolongs lifespan of fruit flies Exp Gerontol 69:189-195 doi:10.1016/j.exger.2015.06.021

Wilkinson JE et al. (2012) Rapamycin slows aging in mice Aging Cell 11:675-682 doi:10.1111/j.1474-9726.2012.00832.x

Wong R, Piper MDW, Wertheim B, Partridge L (2009) Quantification of Food Intake in Drosophila PLOS ONE 4:e6063 doi:10.1371/journal.pone.0006063

$\mathrm{Wu} \mathrm{Q}$ et al. (2020) Sexual dimorphism in the nutritional requirement for adult lifespan in Drosophila melanogaster Aging Cell 19:e13120 doi:10.1111/acel.13120

Xiao C et al. (2019) Expression of Heat Shock Protein 70 Is Insufficient To Extend Drosophila melanogaster Longevity G3 (Bethesda) 9:4197-4207 doi:10.1534/g3.119.400782

Yamaguchi KK, Pereira LF, Lamarão CV, Lima ES, da Veiga-Junior VF (2015) Amazon acai: chemistry and biological activities: a review Food Chem 179:137-151 doi:10.1016/j.foodchem.2015.01.055 


\section{Figure Captions}

Fig. 1 High performance liquid chromatography sample "Aronia": (1) 10.54 min delphinidin (Glu); (2) 13.38 min - delphinidin (Rut); (3) 16.64 min - cyanidin (Glu)

Fig. 2 The effect of ABE on the lifespan, change in median (dM) and maximum (d90\%) lifespan in males of D. melanogaster, throughout the whole lifetime of imago (A, B); at the age of 1-2 weeks old $(C, D)$ and at the age of 4-6 weeks old $(E, F)$. The results of the three replications are presented. The gray background shows the ages of ABE treatment. ${ }^{*} p<0.05-$ Kolmogorov-Smirnov test; ${ }^{*} \mathrm{p}<0.05$ - Mantel-Cox test for median lifespan; Wang-Allison test - maximum lifespan; \#p<0.05 - Wilcoxon-Breslow-Gehan test for median lifespan

Fig. 3 The effect of $A B E$ on the lifespan, change in median (dM) and maximum (d90\%) lifespan in females of D. melanogaster, throughout the whole lifetime of imago (A, B); at the age of 1-2 weeks old (C, D) and at the age of 4-6 weeks old (E, F). The results of the three replications are presented. The gray background shows the ages of ABE treatment. * $p<0.05$ Kolmogorov-Smirnov test; ${ }^{*} \mathrm{p}<0.05$ - Mantel-Cox test for median lifespan; Wang-Allison test - maximum lifespan; \#p<0.05 - Wilcoxon-Breslow-Gehan test for median lifespan

Fig. 4 Effects of the $\mathrm{ABE}$ on the age-related changes of locomotor activity in Drosophila males (A) and females (B), *p<0.05, Student's t-test.

Fig. 5 The effects of $\mathrm{ABE}$ supplementation on the food choice estimated by feeding Preference Index (PI) in males (A, C, E) and females (B, D, F). ABE was supplemented in liquid food obtained by dilution of $30 \mu \mathrm{l}$ of $0.01 \mathrm{mg} / \mathrm{ml}(\mathrm{A}, \mathrm{B}), 2.5 \mathrm{mg} / \mathrm{ml}(\mathrm{C}, \mathrm{D})$, and 10 $\mathrm{mg} / \mathrm{ml}(\mathrm{E}, \mathrm{F}) \mathrm{ABE}$ in $1 \mathrm{ml}$ of $5 \%$ sucrose solution. $\mathrm{PI}=1$ - complete preference for $-\mathrm{ABE}$ control food; $\mathrm{PI}=-1-$ preference for $+\mathrm{ABE}$ experimental food; $\mathrm{PI}=0$ indicating no food preference. ${ }^{*} \mathrm{p}<0.05$, Mann Whitney U-test

Fig. 6 Effects of the ethanolic extract from berries of Aronia melanocarpa on the resistance of Drosophila males (A, C, E) and females (B, D, F) at the age of 14 and 33 days old to oxidative stress (A, B), starvation (C, D), and hyperthermia (E, F). * $p<0.05$ Fisher's exact test

Fig. 7 Effects of $A B E$ treatment on the relative expression level of stress response genes in male $(\mathrm{A}, \mathrm{C})$ and female $(\mathrm{B}, \mathrm{D})$ flies at the age 14 days $(\mathrm{A}, \mathrm{C})$ and 33 days $(\mathrm{B}, \mathrm{D})$. ${ }^{*} \mathrm{p}<0.05$, $* * \mathrm{p}<0.01, * * * \mathrm{p}<0.001, \mathrm{t}-\mathrm{Student}$ test. All diagrams represent the means of three biological replicates, each quantification is carried out in three technical replicates, the error bars show the standard error of the mean. 


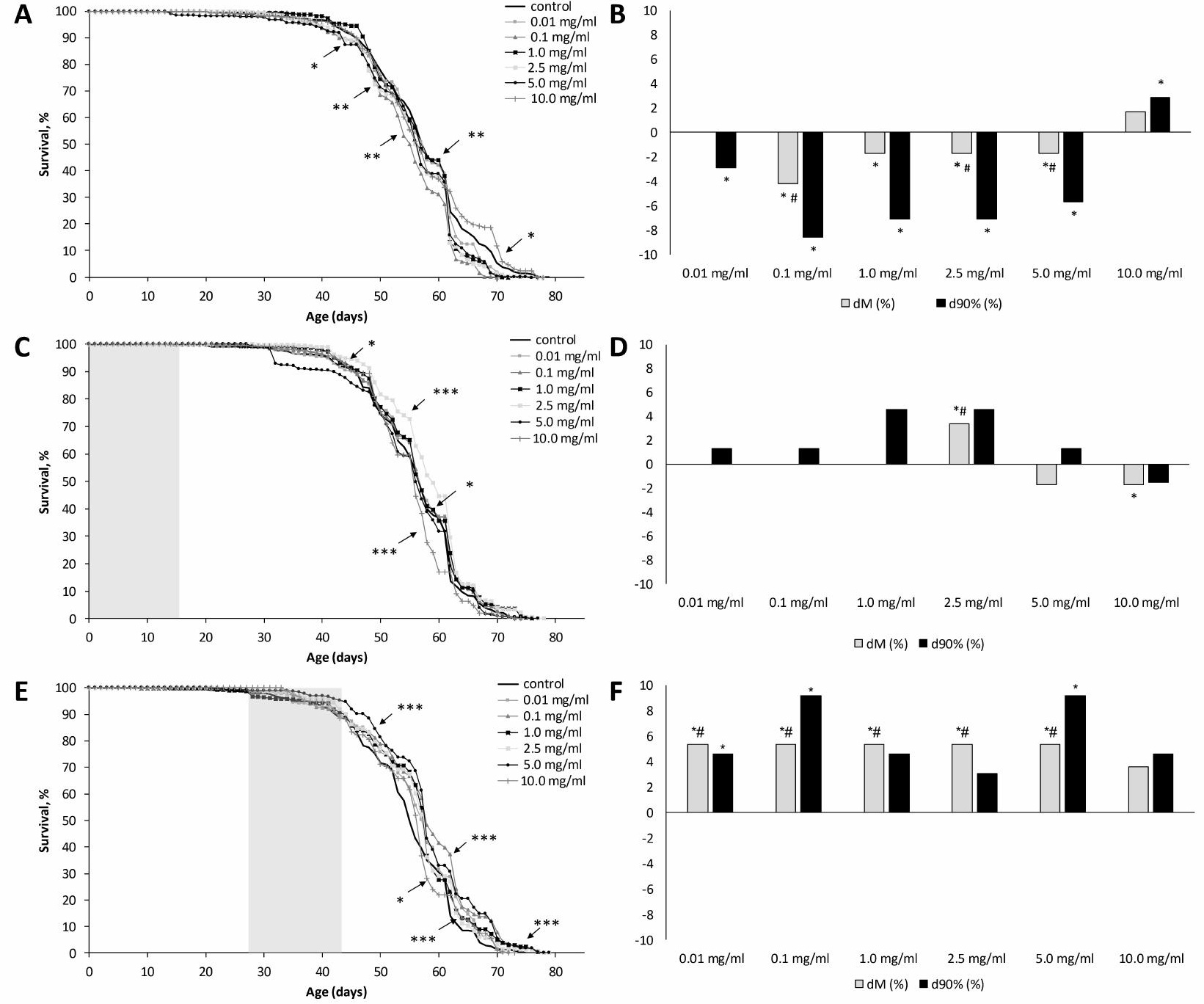




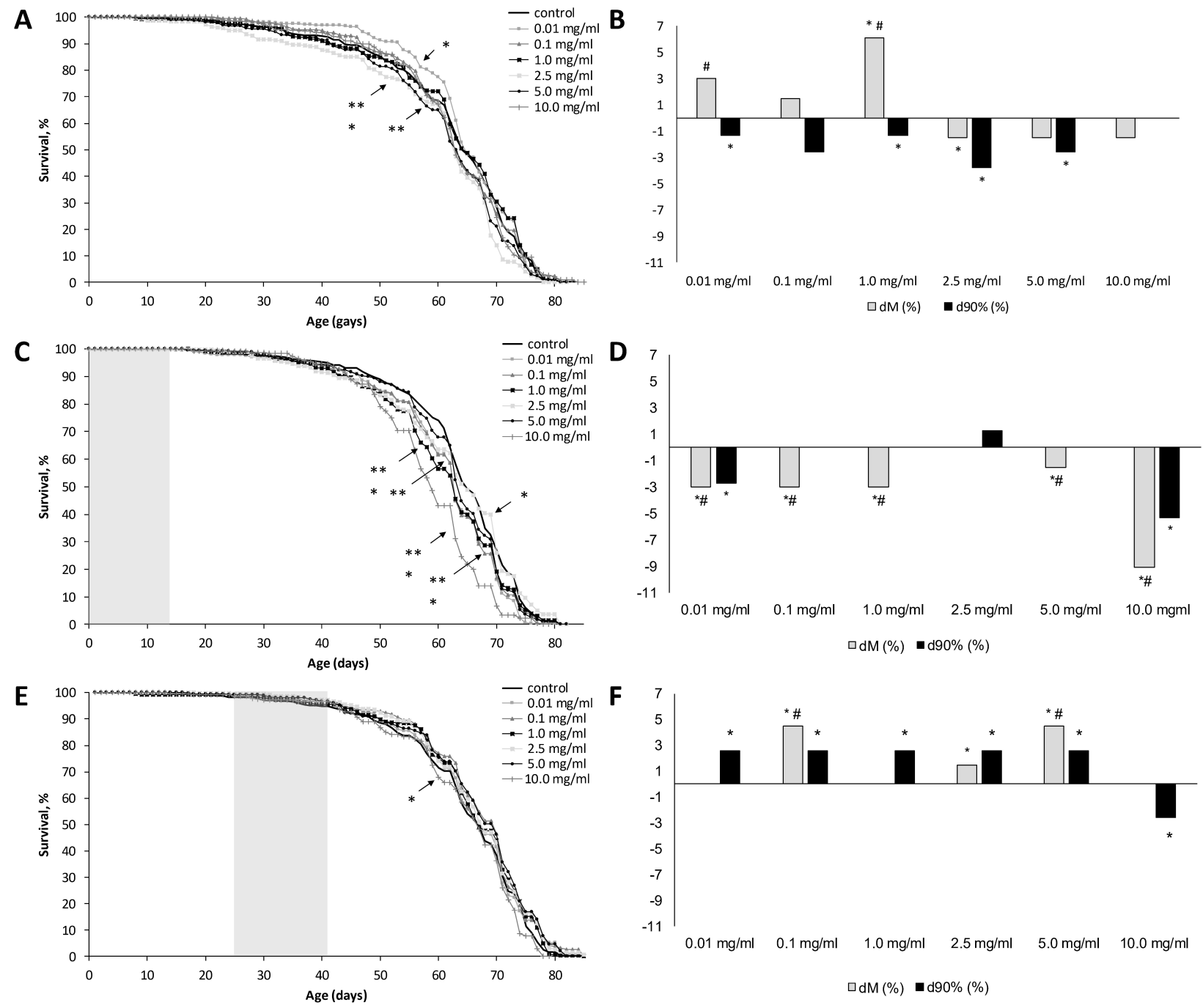


RT: $0.00-24.62$

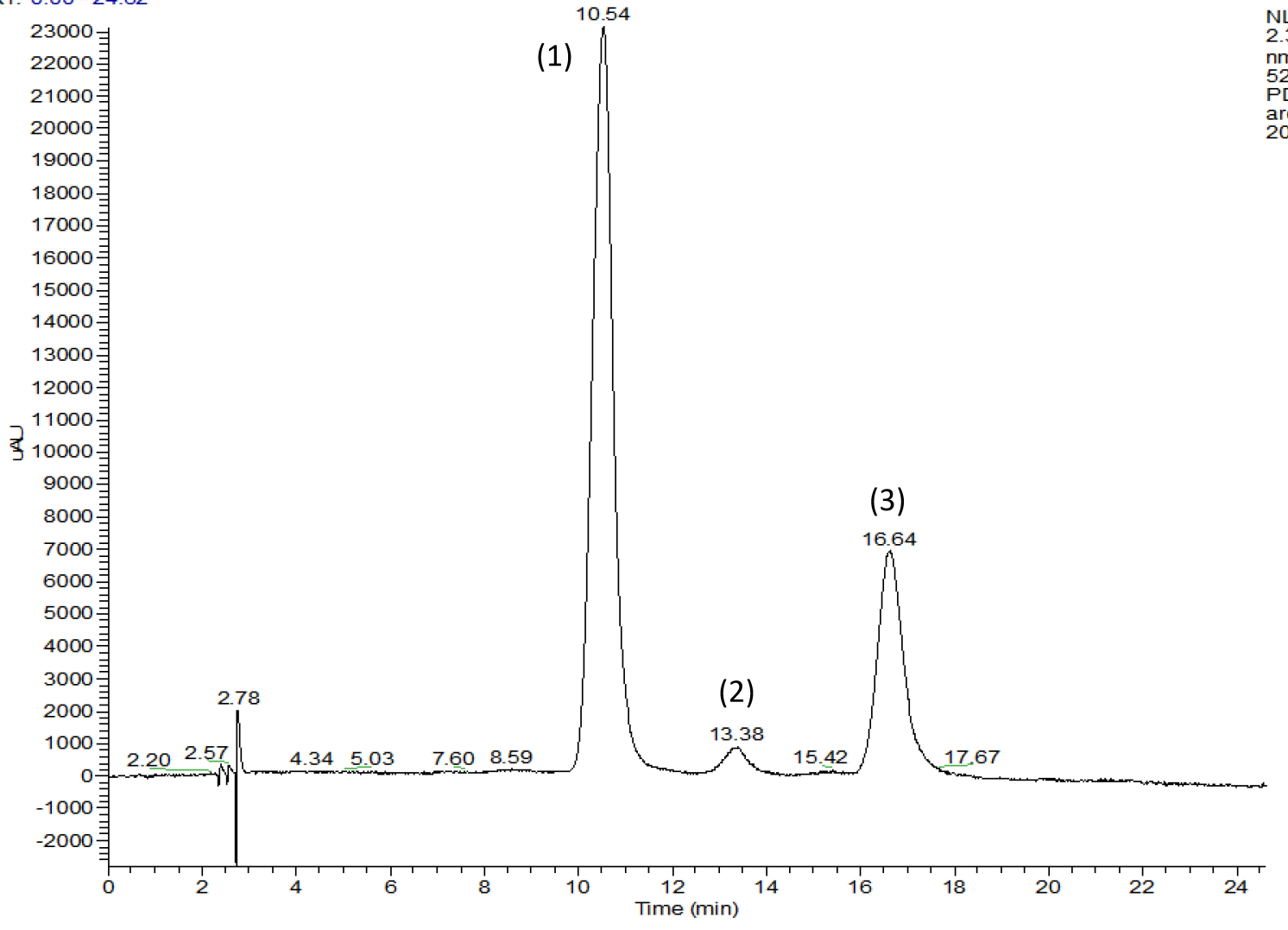

NL:

2.31E4

$\mathrm{nm}=519.3-$ 520.3

PDA

aronia-

2019-12 
males

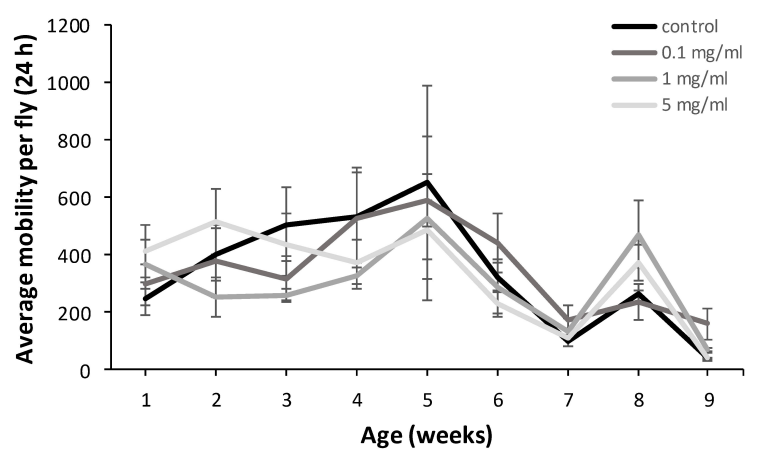

B

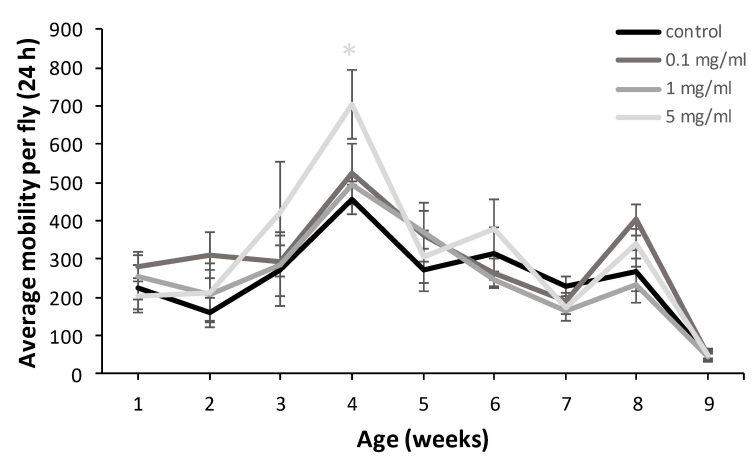


A
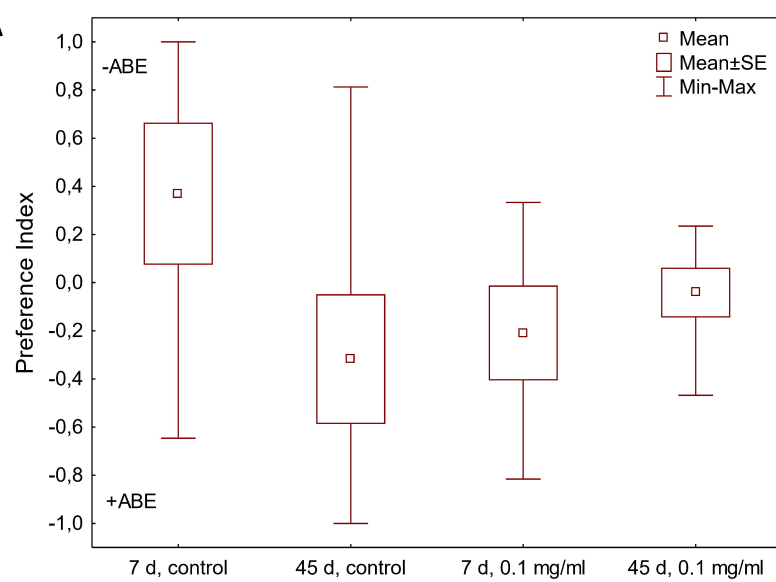

C

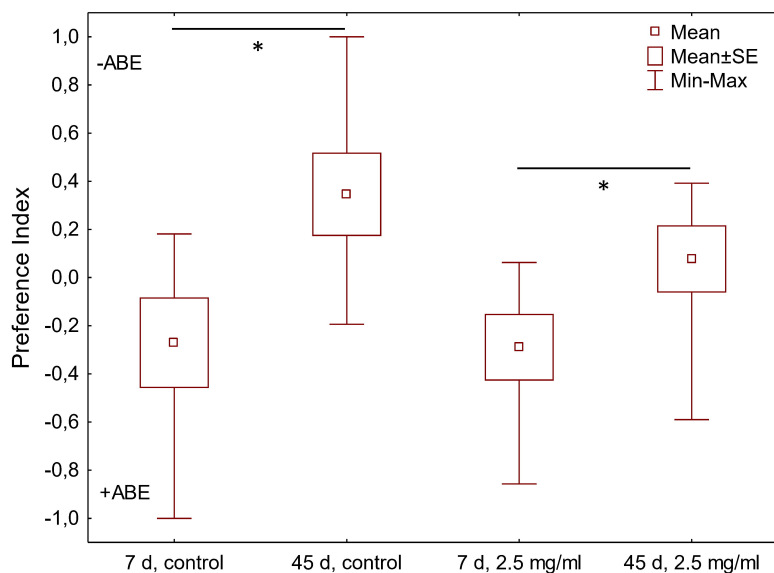

B

D

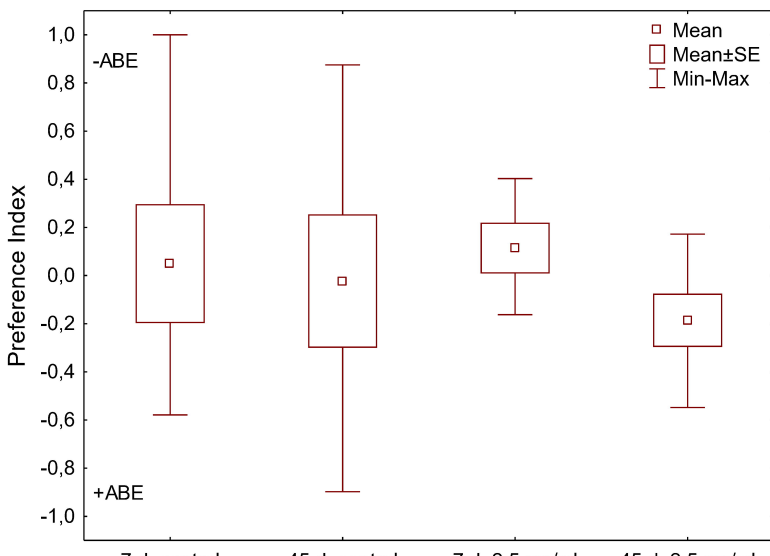

$7 \mathrm{~d}$, control

$45 \mathrm{~d}$, control

$7 \mathrm{~d}, 2.5 \mathrm{mg} / \mathrm{ml}$

$45 \mathrm{~d}, 2.5 \mathrm{mg} / \mathrm{ml}$

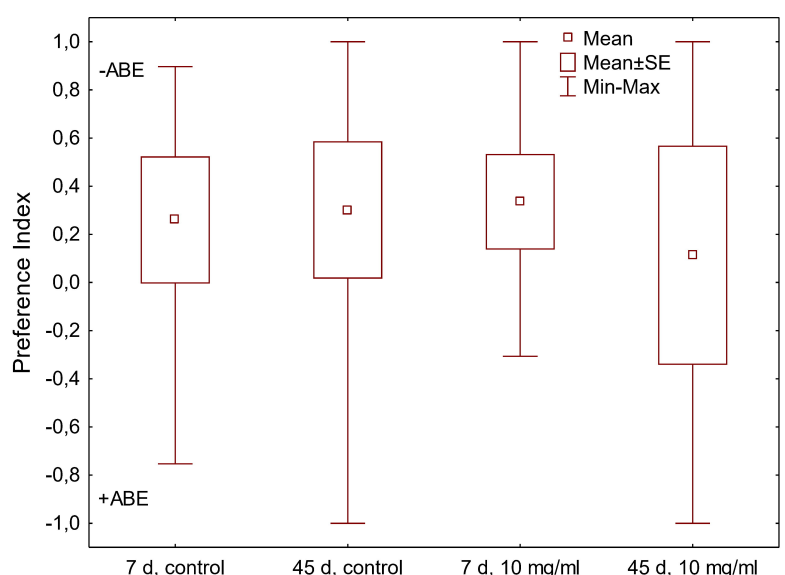

F
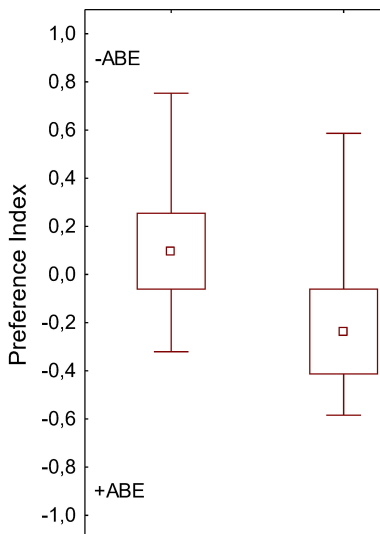

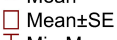

I Min-Max

$7 \mathrm{~d}$, control
Mean
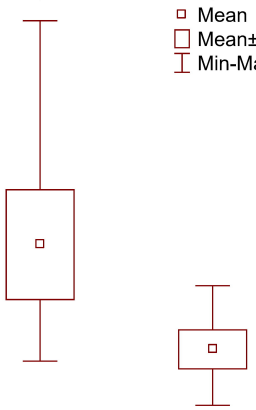
Oxidative stress

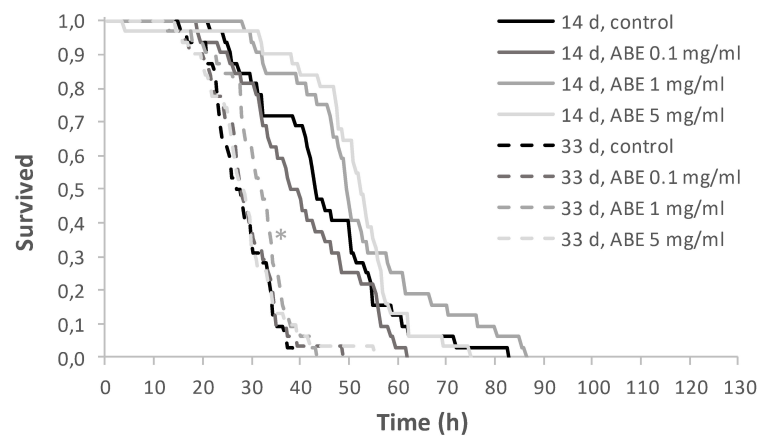

B

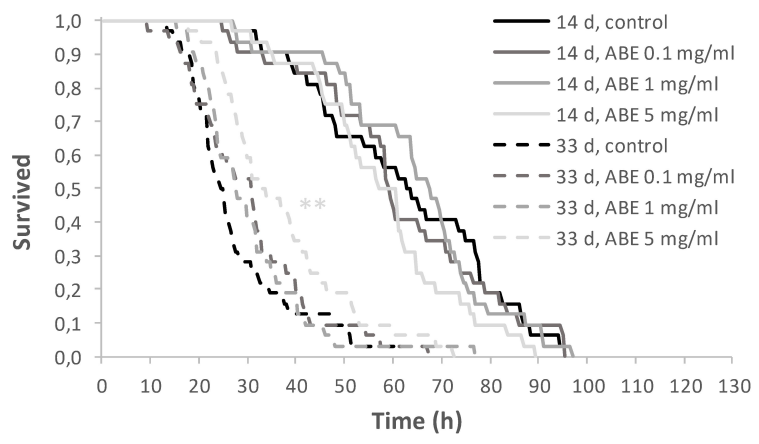

C

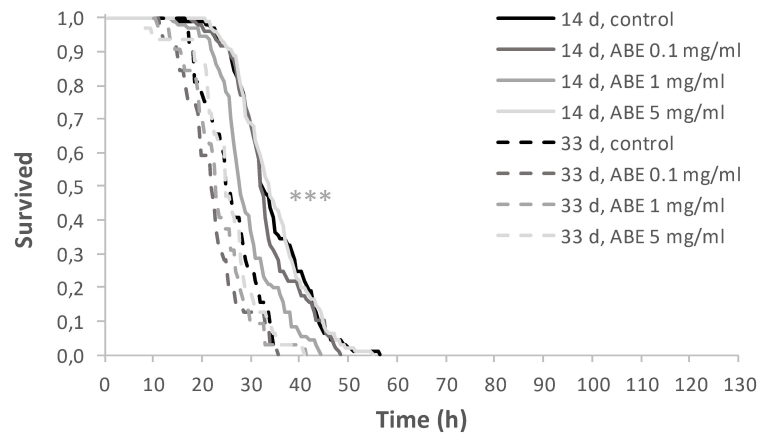

\section{Starvation}

D

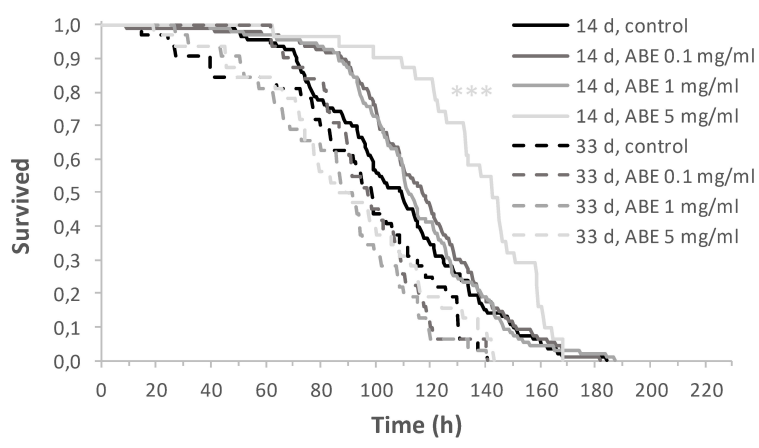

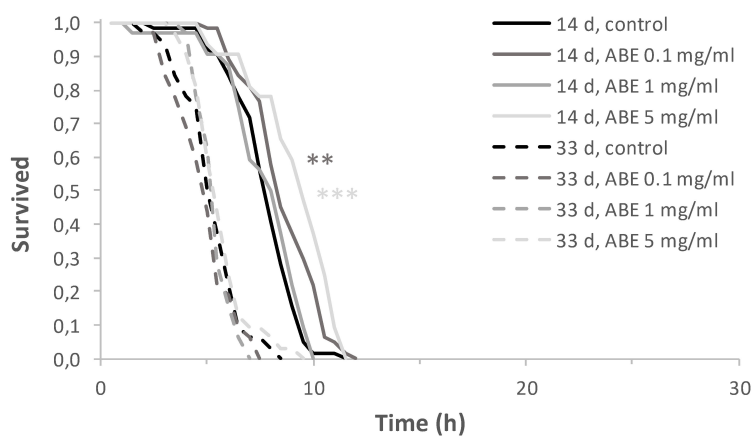

\section{Hyperthermia}

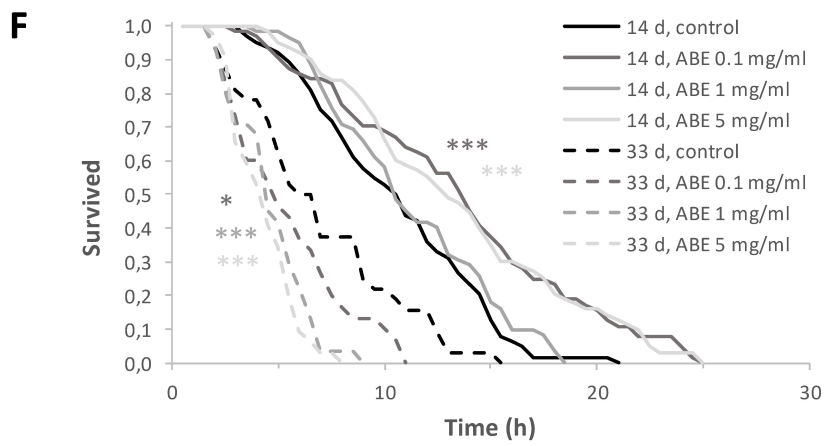

